\title{
O TEXTO LITERÁRIO EM LIVROS DIDÁTICOS DE LÍNGUA PORTUGUESA DO ENSINO FUNDAMENTAL II: ABORDAGENS E PRESENÇA DE PRODUÇÕES REGIONAIS
}

\section{THE LITERARY TEXT IN PORTUGUESE LANGUAGE TEACHING BOOKS OF FUNDAMENTAL EDUCATION II: APPROACHES AND PRESENCE OF REGIONAL PRODUCTION}

\author{
Deise Baggenstoss ${ }^{1}$ \\ Marta Helena Cocco ${ }^{2}$
}

\begin{abstract}
Resumo: Neste artigo, apresentamos resultados de uma pesquisa sobre a proporção da presença do texto literário em relação aos não literários e sobre o modo como o mesmo foi abordado (se para proposição de atividades gramaticais, interpretativas ou reflexivas) em oito volumes de livros didáticos de língua portuguesa distribuídos às escolas públicas pelo Ministério da Educação, bem como sobre a presença ou ausência do texto literário produzido em contexto regional, especificamente em Mato Grosso. Os volumes analisados pertencem às coleções: Tecendo Linguagens, $8^{\circ}$ s e $9^{\circ}$ s anos, autores(as): Tania Amaral Oliveira, Elizabeth Gavioli de Oliveira Silva, Cícero de Oliveira Silva, Lucy Aparecida Melo Araújo, (Editora IBEP); Para Viver Juntos, dos autores(as): Greta Marchetti, Heidi Strecker, Mirella L. Cleto (editora SM); Projeto Teláris, dos autores(as): Ana Trinconi Borgatto, Terezinha Bertin, Vera Marchezi (editora Ática); além da coleção adotada pela escola: Português, Linguagens, dos autores(as): William Cereja e Thereza Cochar (editora Saraiva). Pelos resultados obtidos, constatamos que o único autor regional constante nas coleções é Manoel de Barros e que as abordagens do texto literário contemplam questões de natureza gramatical, interpretativa e reflexiva.
\end{abstract}

Palavras-chave: texto literário, letramento literário, livro didático, literatura mato-grossense.

Abstract: In this article, we present results of a research on the proportion of the presence of the literary text in relation to the non literary ones, on the way in which it was approached (if for proposition of grammatical, interpretative or reflective activities) in eight volumes of language textbooks Portuguese language distributed to public schools by the Ministry of Education, as well as on the presence or absence of the literary text produced in a regional context, specifically in Mato Grosso. The volumes analyzed belong to the following collections: Tecendo Linguagens, $8^{\circ}$ and $9^{\circ}$ years, authors: Tania Amaral Oliveira, Elizabeth Gavioli de Oliveira Silva, Cícero de Oliveira Silva, Lucy Aparecida Melo Araújo, (IBEP Publishing House); To Live Together, by the authors: Greta Marchetti, Heidi Strecker, Mirella L. Cleto (publisher SM); Project Teláris, of the authors: Ana Trinconi Borgatto, Terezinha Bertin, Vera Marchezi (Ática publisher); besides the collection adopted by the school: Portuguese,

\footnotetext{
${ }^{1}$ Professora de Língua Portuguesa da Rede Estadual de Ensino de Mato Grosso. Licenciada em Letras (UNEMAT/ Câmpus de Sinop), especialista em Literatura Infanto-Juvenil (UNEMAT/ Câmpus de Sinop). Mestra do Programa de Mestrado Profissional em Letras (UNEMAT/Campus de Sinop). E-mail: deisebag@ yahoo.com.br.

${ }^{2}$ Professora de Literaturas da Língua Portuguesa da UNEMAT da graduação no câmpus deTangará da Serra e do Mestrado Profletras no câmpus de Sinop. Doutora em Letras e Linguística. Líder do grupo de pesquisas: Literatura, leitura e ensino (UNEMAT/CNPq). E-mail: coccomartahelena@gmail.com.
} 
Languages, of the authors: William Cereja and Thereza Cochar (publisher Saraiva). From the results obtained, we find that the only regional author in the collections is Manoel de Barros and that the approaches of the literary text contemplate issues of grammatical, interpretative and reflexive nature.

Keywords: literary text, literary literacy, textbook, Mato Grosso literature.

\section{Introdução}

A presença do texto literário é fundamental na escola pelo seu potencial de desenvolvimento de habilidades cognitivas e pela sua importância na formação humana. Partindo dessa premissa, a qual acreditamos ser consensual entre os profissionais da área de Letras, decidimos investigar o modo como o texto literário é abordado no livro didático de Língua Portuguesa para o ensino fundamental II. Assim, pesquisamos quatro coleções de Língua Portuguesa distribuídas à escola pelo MEC. Com base em estudos já realizados acerca da leitura literária e das próprias orientações curriculares para o ensino de língua portuguesa, algumas perguntas nortearam nossa pesquisa: de que forma os textos literários são abordados nos livros didáticos? Segundo já apontaram várias pesquisas, são ainda utilizados como pretexto para ensino de gramática? Quais são os gêneros literários mais frequentes? Há presença de textos produzidos no contexto regional de Mato Grosso nos livros didáticos que chegam às escolas estaduais? Para respondê-las, recorremos a uma pesquisa bibliográfica. Salientamos que este artigo é um recorte de uma dissertação do Programa de Mestrado Profissional em Letras PROFLETRAS da UNEMAT, câmpus de Sinop/MT, sob o seguinte título: Poemas e narrativas curtas da literatura mato-grossense: produção de leitura e de textos multimodais, de autoria $\mathrm{e}$ orientação das autoras deste artigo.

A pesquisa ocorreu nos meses de julho a setembro do ano de 2016 na Escola Estadual Olímpio João Pissinati Guerra. Os critérios para seleção foram coleções que já haviam sido utilizadas pela escola objeto dessa pesquisa, totalizando oito volumes. Eis as coleções selecionadas: Tecendo Linguagens, $8^{\circ}$ e $9^{\circ}$ anos, autores(as): Tania Amaral Oliveira, Elizabeth Gavioli de Oliveira Silva, Cícero de Oliveira Silva, Lucy Aparecida Melo Araújo, Editora: IBEP; Para Viver Juntos, dos autores(as): Greta Marchetti, Heidi Strecker, Mirella L. Cleto, editora: SM; Projeto Teláris, dos autores(as): Ana Trinconi Borgatto, Terezinha Bertin, Vera Marchezi; editora Ática; além da coleção adotada pela escola: Português, Linguagens, dos autores(as): William Cereja e Thereza Cochar, editora: Saraiva. 
Assim, conforme demonstraremos ao longo deste artigo, apuramos que, em algumas coleções, algumas atividades acerca dos textos literários ainda têm enfoque apenas na estrutura da língua, isto é, somente fazem abordagem de questões gramaticais. Também observamos nas coleções pesquisadas que o texto literário foi didatizado do mesmo modo que os demais textos, tornando-se um texto didático conforme corroboram Silva e Fritzen (2012). Outro aspecto importante foi a presença do gênero poema com maior incidência, tanto para uso de abordagem gramatical (gráfico 18) quanto para reflexão/motivação (gráfico 17). Por último, encontramos um poema do poeta mato-grossense Manoel de Barros, em mais de 1.400 textos disponíveis. Este dado mostrou-nos que ainda existem lacunas a serem preenchidas em materiais didáticos fornecidos pelo Governo Federal que são distribuídos às escolas públicas do Estado por intermédio do Programa Nacional do Livro Didático (PNLD), sobretudo, relativamente à Literatura produzida em Mato Grosso. Mais adiante, neste artigo, detalharemos melhor os resultados da pesquisa, com a inserção de gráficos.

\section{A presença do texto literário no livro didático: a proporção diante de outros gêneros}

Durante o planejamento das aulas, provavelmente surja a pergunta: o que trabalhar em língua portuguesa? Pela nossa experiência com a docência, acreditamos que muitos professores responderiam que depende do que há disponível no livro didático da turma. Sabemos que o livro didático é um suporte importante para o ensino da língua e da literatura. Mas interessanos saber como esse instrumento didático aborda os textos literários?

Sendo o Brasil um país tão diverso culturalmente, temos a ciência de que é difícil a inclusão de obras literárias de todas regiões nos livros didáticos. Isso já foi apontado no Guia de Livros Didáticos dos anos finais do ensino fundamental: "os textos produzidos nas diversas regiões brasileiras (especialmente Norte, Centro-Oeste e Nordeste) só comparecem muito episodicamente" (BRASIL, 2017, p. 12). Entretanto, para que o ensino acompanhe as transformações sociais e as especificidades culturais da nossa região, como apregoam os Parâmetros Curriculares Nacionais quando incluem o critério de seleção dos textos, é necessária essa inclusão, observados os critérios estéticos e formativos.

Os textos a serem selecionados são aqueles que, por suas características e usos, podem favorecer a reflexão crítica, o exercício de formas de pensamento mais elaboradas e abstratas, bem como a fruição estética dos usos artísticos da linguagem, ou seja, os mais vitais para a plena participação numa sociedade letrada. (BRASIL, 2008, p. 24) 
O Programa Nacional do Livro Didático (PNLD) tem como principal objetivo subsidiar o trabalho pedagógico dos professores por meio da distribuição de coleções de livros didáticos aos alunos da educação básica ${ }^{3}$. Considerando um país tão grande como o nosso, com tantas diferenças geradas pela desigualdade social, faz-se necessária uma política pública que invista em subsídio/apoio para o professor em sala de aula. Certamente há vantagens e desvantagens nessa produção de cunho didático, o que torna questionáveis algumas escolhas, se são melhores ou piores para os estudantes, entretanto, é inegável a importância desse material, uma vez que em muitos lugares não existem condições minimamente adequadas de ensino e de aprendizagem e, menos ainda, de o professor elaborar seu próprio material didático, seja pela falta de tempo para pesquisa e produção, ou até mesmo pelas lacunas devido às falhas em sua formação, assunto que mereceria melhor desenvolvimento, mas não é objetivo deste artigo.

Assim, ao pesquisarmos os livros didáticos, o que constatamos é que eles acabam, de certa forma, unificando a aprendizagem, pois têm eixos de ensino comuns. A diferença entre uma coleção e outra é a forma como cada autor aborda os conteúdos.

Nos $8^{\circ} \mathrm{s}$ e $9^{\circ} \mathrm{s}$ anos do ensino fundamental, o livro didático de língua portuguesa versa, além das questões gramaticais, sobre o trabalho com os diversos gêneros. Nesse aspecto, tivemos o propósito de constatar a proporção da presença do texto literário em relação aos outros gêneros, e quais abordagens de produção de leitura são feitas nos livros didáticos. Outro objetivo foi verificar se o texto produzido em contexto mato-grossense ${ }^{4}$ integra tal material. Sabemos que o texto literário é um componente muito importante no ensino da língua portuguesa, uma vez que os Parâmetros Curriculares Nacionais abordam e salientam sua relevância, bem como reforçam que não devem ser usados para pretexto ${ }^{5}$ no tratamento de questões morais ou tópicos gramaticais:

O tratamento do texto literário oral ou escrito envolve o exercício de reconhecimento de singularidades e propriedades que matizam um tipo particular de uso da linguagem. É possível afastar uma série de equívocos que costumam estar presentes na escola em relação aos textos literários, ou seja, tomá-los como pretexto para o tratamento de questões outras (valores morais, tópicos gramaticais) que não aquelas que contribuem para a formação de leitores capazes de reconhecer as sutilezas, as

\footnotetext{
${ }^{3}$ Disponível em: <http://portal.mec.gov.br/pnld/apresentacao〉. Acesso em: 07setembro 2016.

${ }^{4}$ São considerados textos de literatura mato-grossense "os textos escritos por autores que nasceram em Mato Grosso ou que nele residem (ou tenham residido), contribuindo para o enriquecimento da cultura do Estado." (MAGALHÃES, 2001, p. 18).

${ }^{5}$ Nesta pesquisa, utilizou-se o termo pretexto no sentido que os Parâmetros Curriculares Nacionais abordam, como uma desculpa para abordagem gramatical, não levando em consideração outras reflexões que podem ser exploradas com o texto literário.
} 
particularidades, os sentidos, a extensão e a profundidade das construções literárias. (BRASIL, 1998, p. 27)

Assim, fizemos uma pesquisa bibliográfica para verificar como o texto literário é abordado nos livros didáticos. Ponderamos que, em se tratando da metodologia adotada pelo livro didático, o desempenho do professor como mediador da leitura pode alterar a abordagem do texto literário, por exemplo: há poemas usados no livro didático somente para preencher as lacunas com as preposições e/ou outra classe gramatical. Entretanto, se o professor quiser ampliar essa abordagem, poderá propiciar a leitura cursiva, que considera aspectos interativos emocionais, bem como a analítica, que valoriza uma interpretação mais aprofundada, ambas teorizadas por Annie Rouxel (2012, 2013a). Deste modo, o texto literário não se torna um mero texto escolar:

Portanto, se concordarmos com a abordagem trazida pelo livro didático que sugere uma leitura a fim de que a realização de um exercício seja possível, teremos em mãos um texto escolar; no entanto, se ignorarmos a atividade sugerida e simplesmente lermos o texto trazido pelo compêndio, teremos novamente um texto literário. (SILVA, FRITZEN, 2012, p. 272)

Logo, salientamos que o livro didático de língua portuguesa ao didatizar ${ }^{6}$ o texto literário da mesma forma que os demais textos, torna-o comum, perde seu encantamento, sua peculiaridade, sua visão humanizadora, entre outros. Zilberman adverte que, dependendo do modo como o texto é trabalhado, pode levar a uma leitura imposta, sem que o leitor consiga estabelecer um diálogo com a obra e viva a experiência que ela pode propiciar:

[...] o autoritarismo se apresenta de modo mais cabal, quando o livro didático se faz portador de normas linguísticas e do cânone literário. Ou quando a interpretação se imobiliza em respostas fechadas, de escolha simples, promovidas por fichas de leitura, sendo o resultado destas a anulação da experiência pessoal e igualitária com o texto. (ZILBERMAN, 2009, p. 35)

Novamente, reforçamos que o professor de literatura e/ou língua portuguesa tem a possibilidade de criar/inventar outras leituras a partir dos textos literários presentes no livro didático, mas devido a vários fatores ${ }^{7}$ há uma espécie de abdicação do texto literário em sala de

\footnotetext{
${ }^{6}$ Aqui, referimo-nos aos livros didáticos apresentados nesta pesquisa.

${ }^{7}$ Alguns fatores: jornada de trabalho extensa, com isso falta tempo para preparar atividades diferenciadas do livro didático; formação do profissional deficitária em metodologias diferenciadas; falta de políticas públicas voltadas para o fazer pedagógico, exemplo: Sala do Educador, usada como formação continuada nas escolas públicas matogrossenses, focada mais nas leituras de normativas, leis, deixando de lado as práticas metodológicas.
} 
aula, da sua singularidade, das suas características estéticas, da sua linguagem metafórica ou do sentimento que pode ser despertado ao lê-lo.

Deste modo, constatamos que, apesar da diversidade de gêneros presentes no livro didático, o texto literário foi didatizado de modo semelhante aos demais textos, exceto os nomeados nesta pesquisa como reflexão, ficando a critério do professor regente sua abordagem. Como afirmam Silva e Fritzen (2012, p. 272, grifo dos autores), “o texto literário é abordado pelos livros didáticos de tal forma que acaba por dissociá-lo de sua qualidade artística, não pragmática. Atribuindo-lhe uma função imediata, um texto literário transforma-se em mero texto didático ”. Buscando analisar melhor esse material didático, pesquisamos quatro ${ }^{8}$ coleções novas $^{9}$, todas aprovadas pelo Ministério da Educação e Cultura ${ }^{10}$, para os $8^{\circ}$ s e $9^{\circ}$ s anos, sendo que destas, duas ${ }^{11}$ foram selecionadas pela escola para o próximo triênio. Eis alguns critérios de tabulação da pesquisa:

Foram catalogados todos os textos presentes nos livros didáticos pesquisados, incluindo fragmentos e textos multimodais ${ }^{12}$. Os gêneros literários pesquisados foram: poema ${ }^{13}$, crônica, romance ${ }^{14}$, conto, lenda, canção ${ }^{15}$, peça teatral e fábula. No item "Outros textos", está o total de textos diversos gêneros, excluindo os literários analisados. Todas as coleções fizeram a abordagem do texto literário para interpretação textual ${ }^{16}$, bem como interpretação e gramática - alguns livros incluíram, após a interpretação, fragmentos do texto para explicar questões gramaticais, então foram consideradas as duas abordagens juntas. Algumas coleções também utilizam o texto literário somente para propor questões gramaticais, o que foi legendado como

\footnotetext{
${ }^{8}$ Coleção 1: TECENDO LINGUAGENS, $8^{\circ}$ e $9^{\circ}$ anos, autores(as): Tania Amaral Oliveira, Elizabeth Gavioli de Oliveira Silva, Cícero de Oliveira Silva, Lucy Aparecida Melo Araújo, Editora: IBEP. Coleção2: PARA VIVER JUNTOS, dos autores(as): Greta Marchetti, Heidi Strecker, Mirella L. Cleto, editora: SM. Coleção3: PORTUGUÊS, LINGUAGENS, dos autores(as): William Cereja e Thereza Cochar, editora: Saraiva. Coleção 4: PROJETO TELÁRIS, dos autores(as): Ana Trinconi Borgatto, Terezinha Bertin, Vera Marchezi; editora Ática.

${ }^{9}$ Coleções que foram disponibilizadas para avaliação dos professores, entre elas, as duas escolhidas para os próximos três anos na escola Olímpio João Pissinati Guerra.

${ }^{10}$ Ver guia do Programa Nacional do Livro Didático (PNLD) 2017.

${ }^{11}$ As escolas selecionam duas opções de coleções de livros didáticos, se não vier a primeira, provavelmente virá a segunda opção.

12 O termo "texto multimodal" tem sido usado para nomear textos constituídos por combinação de recursos de escrita (fonte, tipografia), som (palavras faladas, músicas), imagens (desenhos, fotos reais) gestos, movimentos, expressões faciais etc. (BUZEN, MENDONÇA. 2013, p. 21).

${ }^{13}$ A literatura de cordel foi incluída nesse item.

${ }^{14}$ A novela foi incluída nesse item.

15 Apesar dos gêneros poema e canção terem a mesma origem, na pesquisa foram classificados separados, conforme abordam os livros didáticos.

${ }^{16}$ Não foi separado a interpretação da compreensão, alguns autores dos livros didáticos pesquisados abordam somente como interpretação, outros como interpretação e compreensão. Foram considerados como sinônimos nesta pesquisa.
} 
gramática. Houve também a ocorrência de o texto literário servir como inspiração ou motivação sobre um assunto ou tema debatido, sendo classificado na pesquisa como reflexão. As imagens visuais que ilustraram o texto não foram consideradas, entretanto, as que serviam de reflexão e/ou análise foram consideradas como texto ${ }^{17}$.

No primeiro conjunto de gráficos dos $8^{\circ} \mathrm{s}$ anos (gráficos 1,2,3 e 4), nomeamos cada coleção e mostramos a quantidade de textos, tanto os literários quanto os não literários ${ }^{18}$. Assim, pudemos constatar que poema é o gênero literário mais utilizado pelos livros didáticos. Isso se deve porque muitos servem de motivação para abordar algum assunto, mas também foram utilizados somente para pretexto ${ }^{19}$.

Gráfico 1

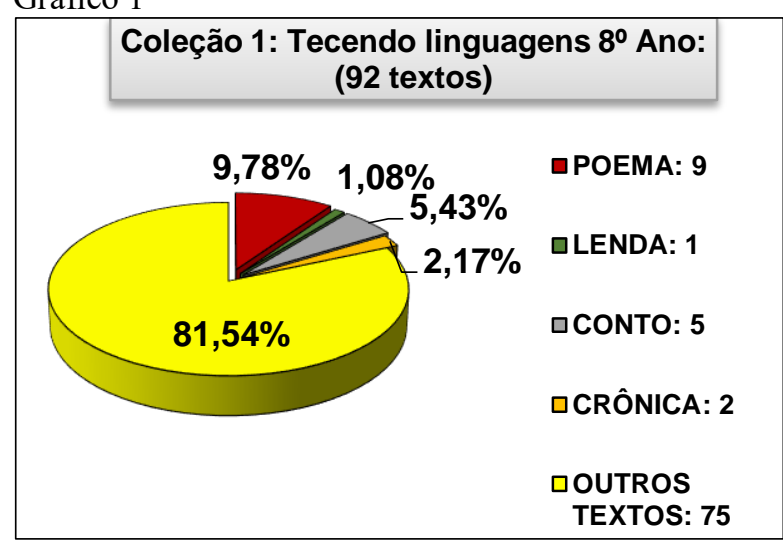

Gráfico 3

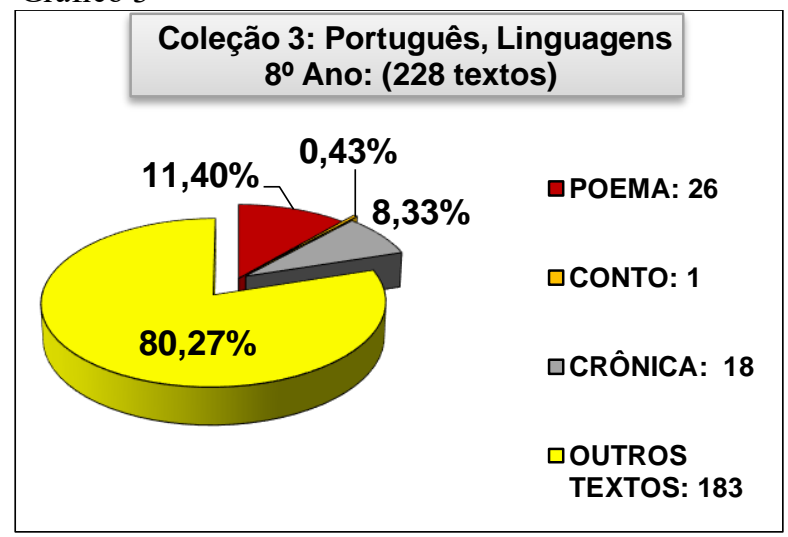

Gráfico 2

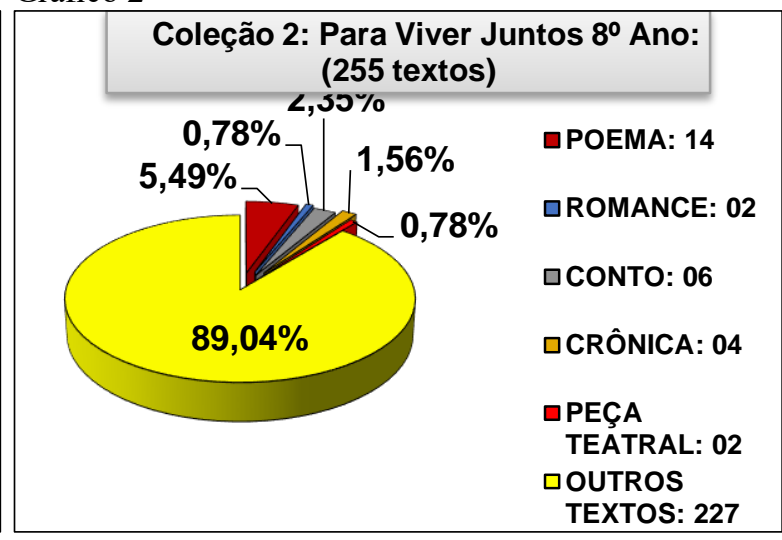

Gráfico 4

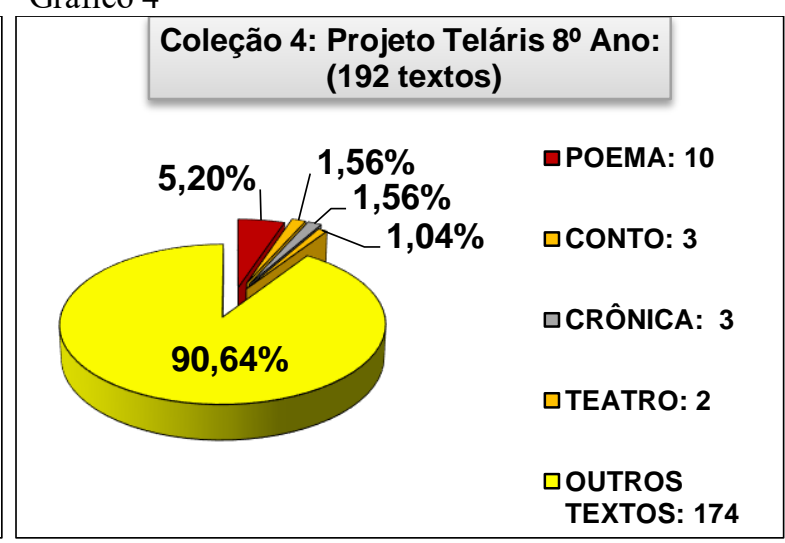

\footnotetext{
${ }^{17}$ Concepção de texto para esta pesquisa: "o texto é um evento comunicativo em que estão presentes os elementos linguísticos, visuais e sonoros, os fatores cognitivos e vários aspectos. É, também, um evento de interação entre locutor e interlocutor, os quais se encontram em um diálogo constante", (CAVALCANTE, 2016, p. 20).

${ }^{18}$ Outros textos.

${ }^{19}$ Ler citação (BRASIL, 1998, p. 27).
} 
Dando sequência, temos o segundo conjunto de gráficos dos $8^{\circ} \mathrm{s}$ anos (gráficos 5,6,7 e 8), cujo objetivo foi analisar o percentual de textos literários nos livros didáticos e como ocorre a abordagem dos mesmos. Deste modo, constatamos que os livros didáticos estão contemplando diversos gêneros textuais:

\begin{abstract}
Afinal, ainda que não tenha sido esta a intenção original, o imperativo da diversidade de gêneros e tipos (um dos critérios da Avaliação oficial do LDP) tem significado, muitas vezes, o abandono do texto literário - antes praticamente solitário, no LDP 20 e na sala de aula de língua materna - em favor dos demais. Num contexto como este, o velho hábito de não contemplar o que o texto literário tem de próprio, quando confrontado com os outros, só tem feito aumentar o esquecimento da literatura e a sensação, cada vez mais disseminada, de que é "difícil" ou mesmo "impossível" para o ensino fundamental. (RANGEL, 2003, p. 133, grifo do autor)
\end{abstract}

Assim, analisamos que não há uma homogeneidade no que tange à abordagem do texto literário $^{21}$, cada coleção se concentrou mais em um aspecto. A coleção 1, por exemplo, só utilizou $17,65 \%$ para abordagem gramatical, além da interpretação; já na coleção 2 , temos praticamente o oposto, pois apenas em $21,46 \%$ dos textos a abordagem foi para interpretação, o restante, $78,54 \%$, recebeu algum tipo de abordagem gramatical. Um aspecto importante é que, quanto à interpretação e gramática, todas as coleções primeiramente apresentaram as questões relacionadas à interpretação, depois introduziram o conteúdo gramatical para em seguida utilizar-se de exemplos retirados do texto literário, comprovando que o texto literário ainda é muito utilizado para uso e exemplificação das regras gramaticais.

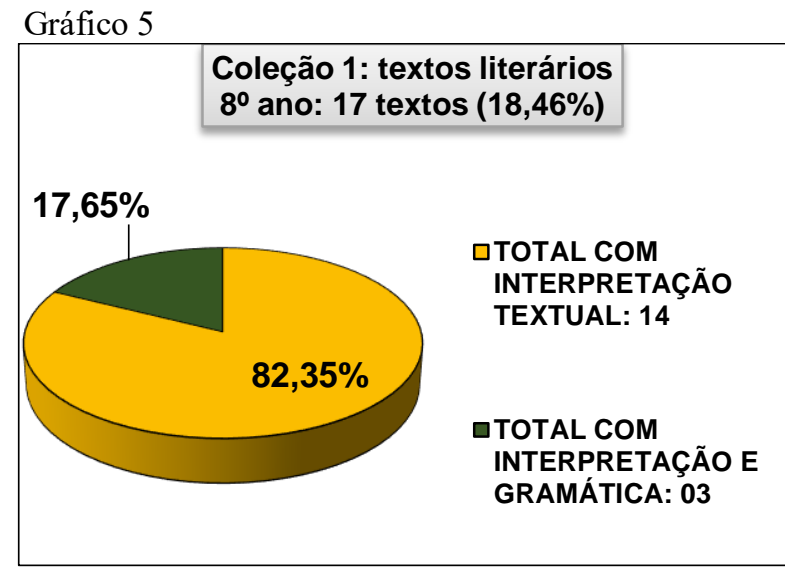

Gráfico 7

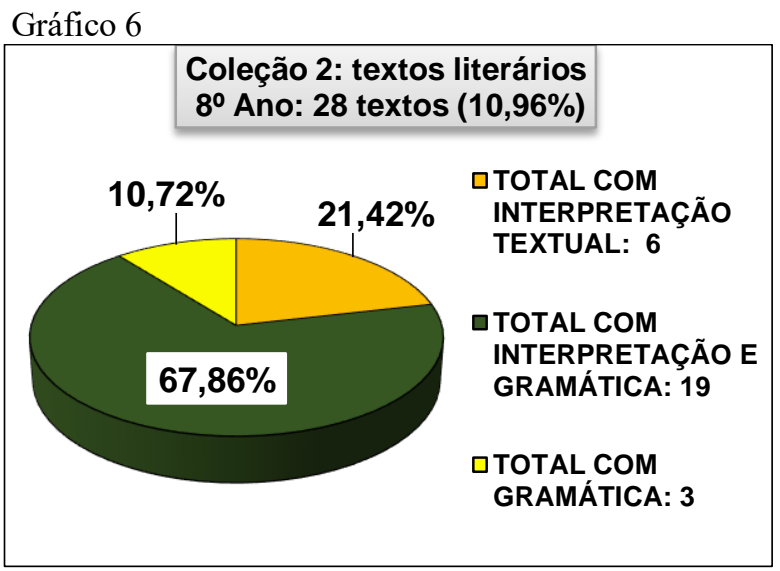

Gráfico 8

\footnotetext{
${ }^{20}$ Livro didático de língua portuguesa.

${ }^{21}$ Não se pesquisou os demais gêneros presentes em cada coleção.
} 

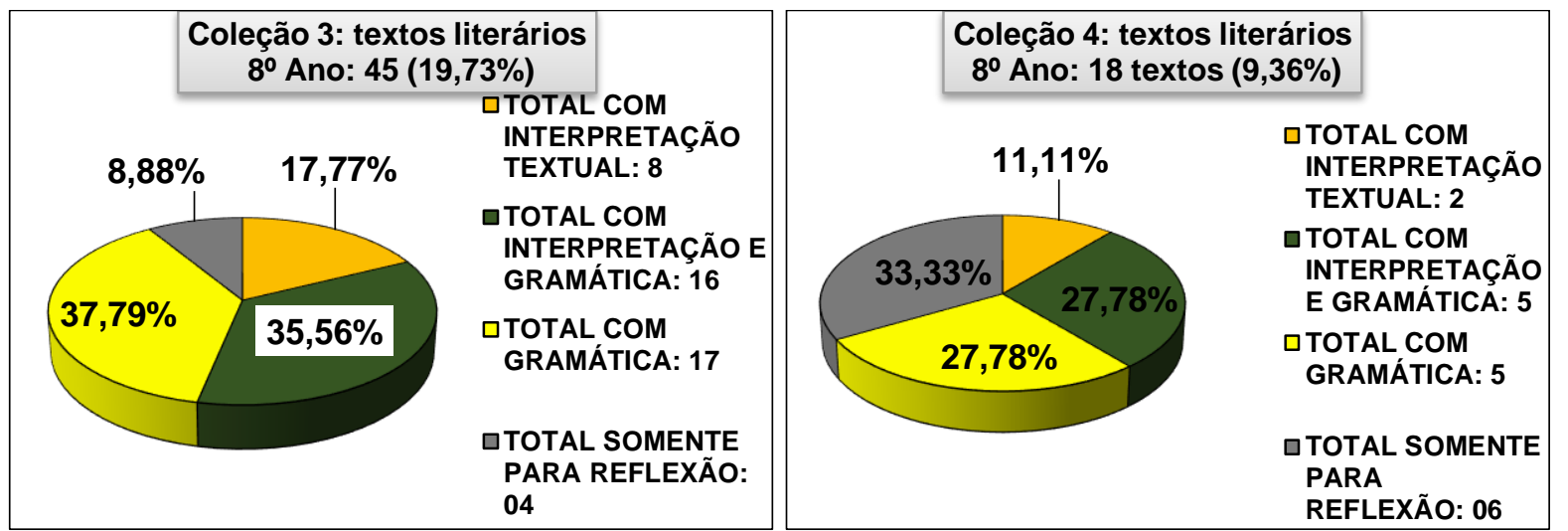

Neste terceiro conjunto de gráficos, os dos $9^{\circ}$ s ano (gráficos 9,10,11 e 12), observamos uma disparidade muito grande na quantidade de textos literários abordados. Temos na coleção $2^{22}$ apenas 5,95\% do total de textos, e, de outro lado, a coleção 3 com $24,01 \%$ de textos literários. Um aspecto importante é a equidade das coleções 1, 3 e 4 na quantidade de textos literários. Também é necessária uma observação: nos $9^{\circ} \mathrm{s}$ anos há o estudo das Figuras de Linguagem, isso motivou o uso dos textos literários, em especial o poema para exemplificação ou proposição de atividade.

Gráfico 9

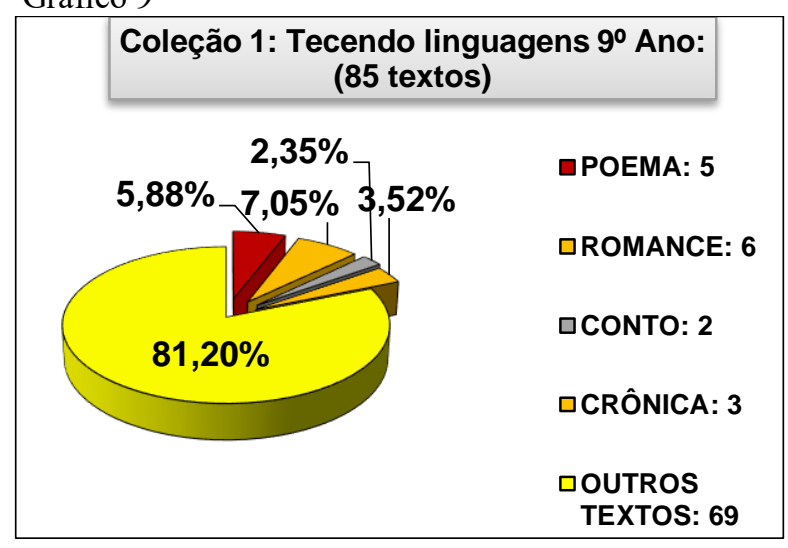

Gráfico 11
Gráfico 10

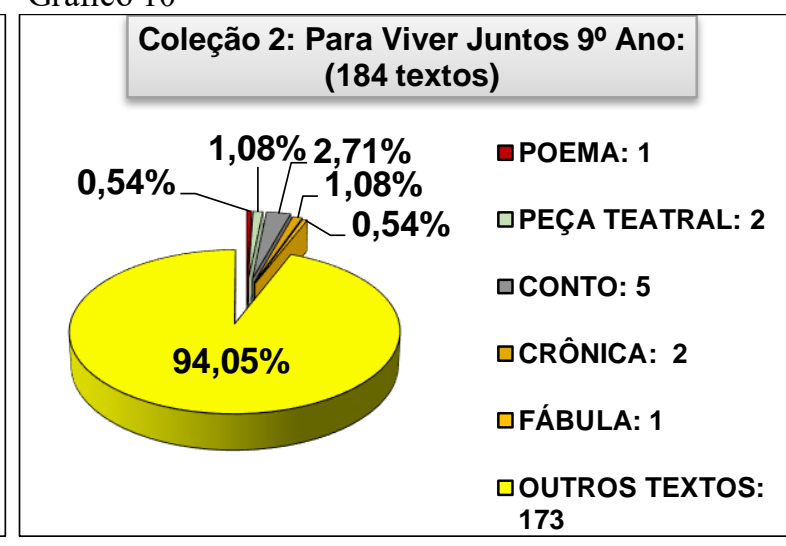

Gráfico 12

\footnotetext{
${ }^{22}$ Essa coleção trabalha um gênero por unidade, não privilegiou os gêneros literários analisados.
} 

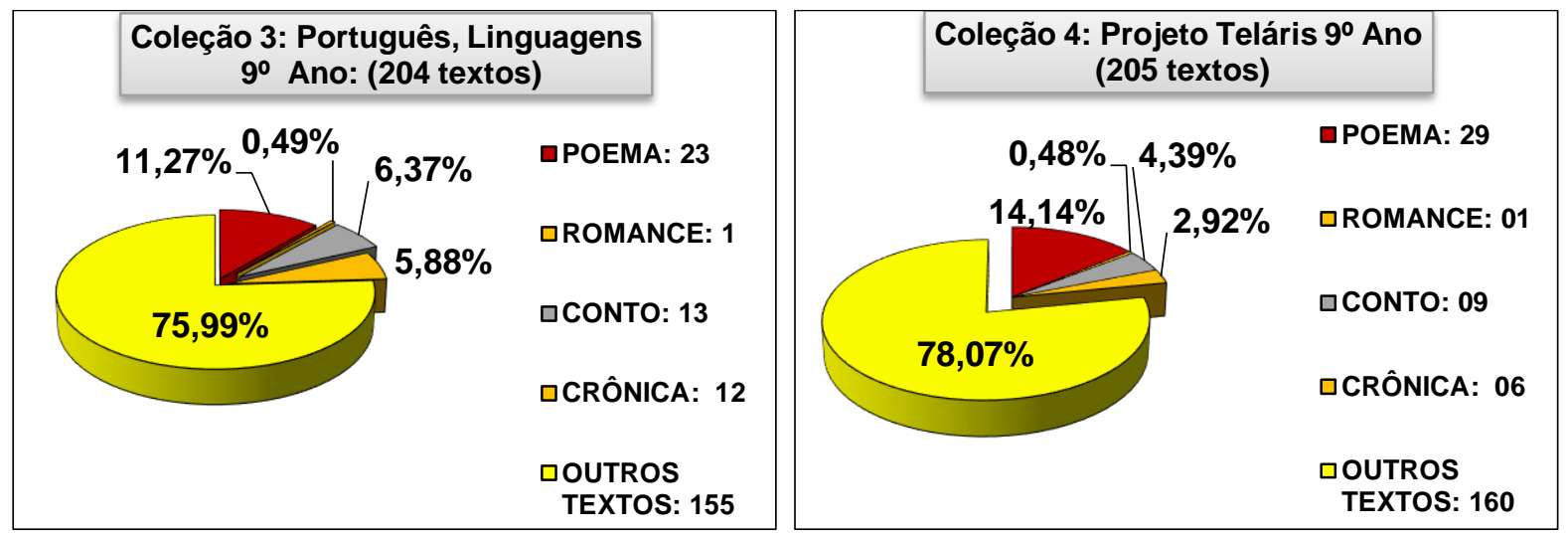

Quanto ao conjunto de gráficos dos $9^{\circ}$ s anos a seguir (gráficos 13,14,15 e 16), podemos observar que ocorreu um aumento considerável no percentual dos textos literários, quase 5\% nas coleções 1,3 e 4, entretanto a coleção 2 obteve uma queda de 5\%. Uma justificativa para isso é que nesse ano, os livros didáticos abordam as figuras de linguagem, conforme mencionamos anteriormente.

Gráfico 13

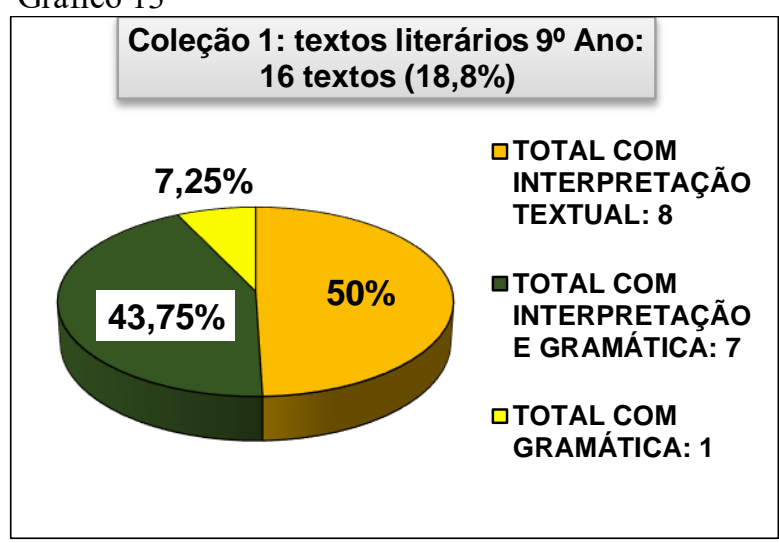

Gráfico 14

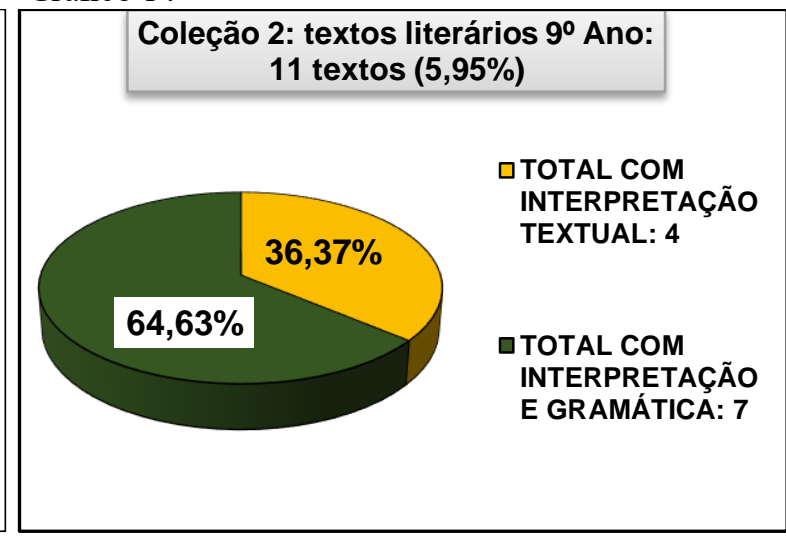



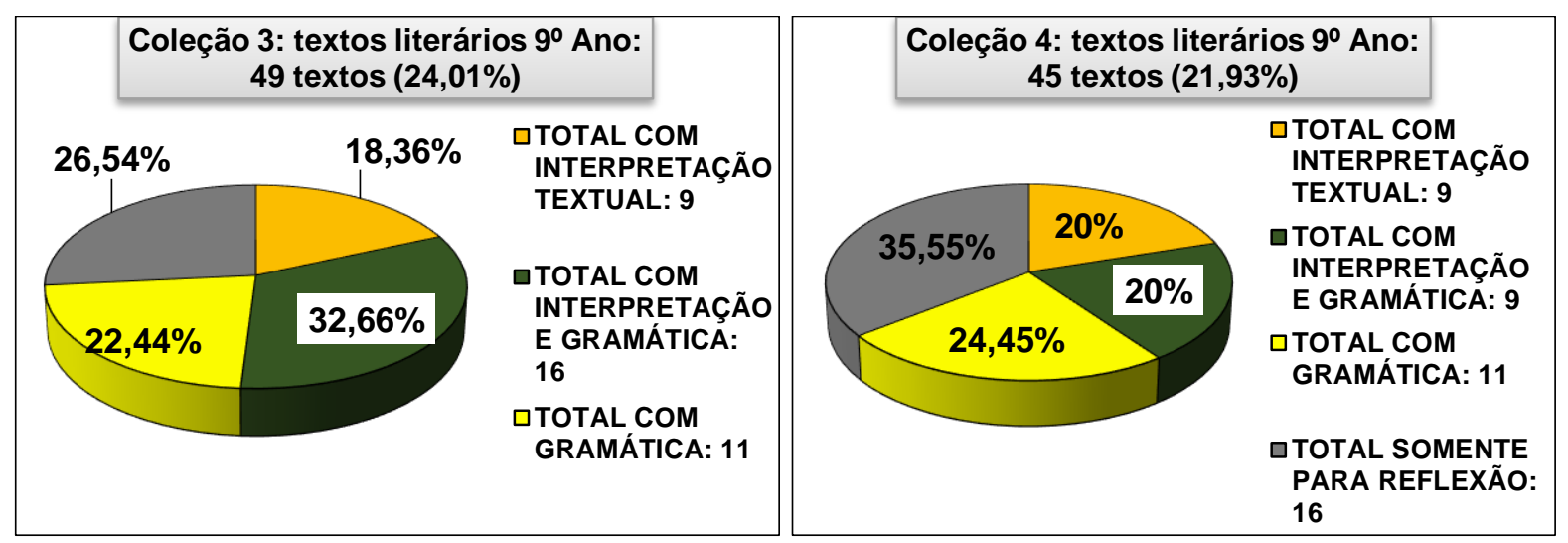

Com o propósito de saber quais os gêneros literários são usados em atividades de motivação e quais são mais utilizados como pretexto para o ensino da gramática, fizemos os dois gráficos seguintes. $\mathrm{O}$ gênero poema foi o mais utilizado, tanto em relação à motivação, como também em questões gramaticais.

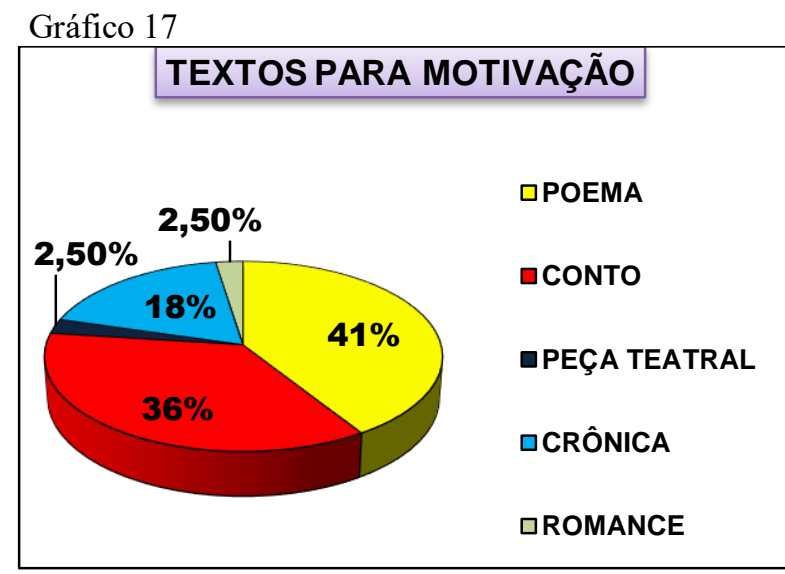

Gráfico 18

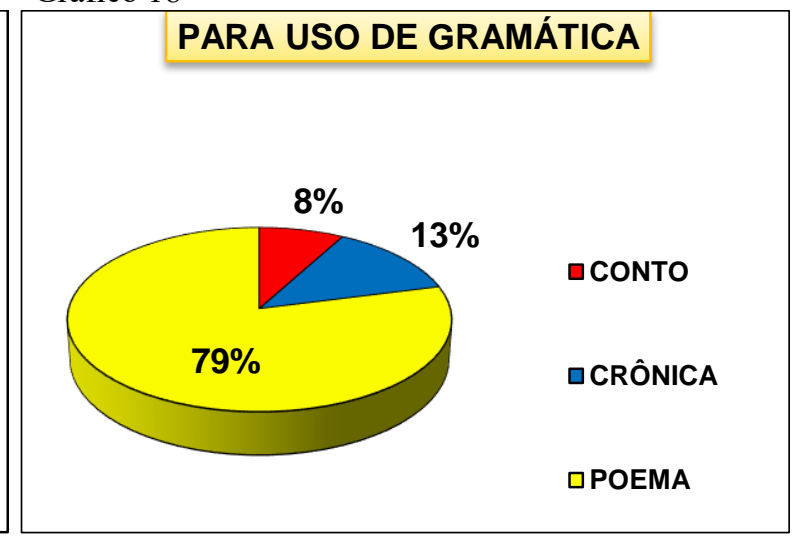

Certamente, o professor de língua portuguesa pode fazer toda diferença no que diz respeito ao trato do texto literário, em especial o poema/poesia e sua função social, tão defendida pelo professor Hélder Pinheiro em seu livro Poesia em sala de aula:

\footnotetext{
A função social da poesia, é bom lembrar, não é mensurável dentre modelos esquemáticos. Trata-se de uma experiência íntima que muitas vezes captamos pelo brilho do olhar de nosso aluno na hora de uma leitura, pelo sorriso, pela conversa de corredor. (PINHEIRO, 2007, p.23)
}

Salientamos que o objetivo principal desta pesquisa, não foi apresentar erros e/ou falhas na elaboração dos livros didáticos, mas sim, fazer um levantamento de como os textos literários são abordados e, principalmente, se textos produzidos em Mato Grosso estão contemplados nos livros pesquisados. Descobrimos a presença apenas de um poema de Manoel de Barros, conforme gráfico abaixo: 


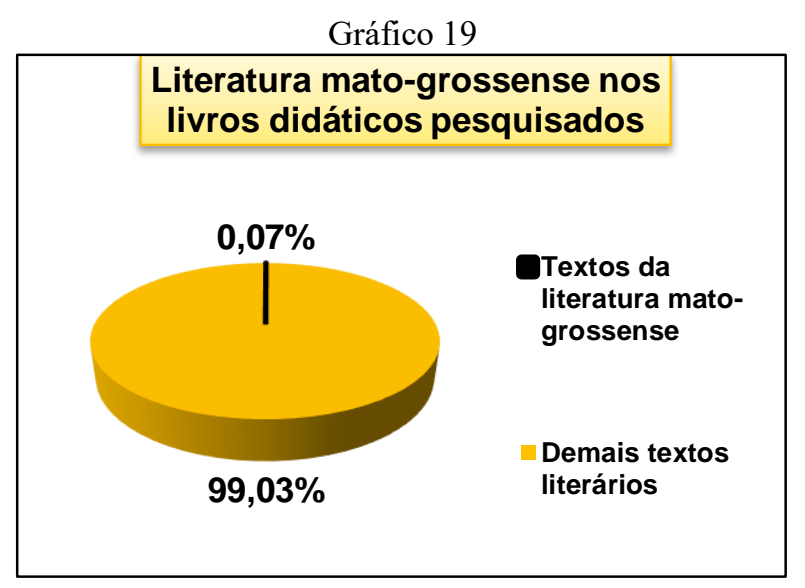

Chegamos à conclusão que, nas quatro coleções pesquisadas, em se tratando do texto literário, a presença não é tão expressiva em relação a outros gêneros. Por isso, a escola precisa criar projetos de leitura, para que a formação do leitor não seja circunscrita ao livro didático, incluindo obras do contexto regional, uma vez que estas estão praticamente ausentes e também são importantes, conforme discorremos no item seguinte.

\section{Literatura regional e sua importância no contexto escolar}

A literatura nos mostra o "mundo compreensível transformando sua materialidade em palavras de cores, odores, sabores e formas intensamente humanas" (COSSON, 2012, p. 17). Por ser essencialmente humana, a literatura deve ser experimentada e vivenciada pelos nossos estudantes. Sendo assim, como proporcionar aos estudantes uma apropriação de sentidos literários com textos produzidos em Mato Grosso? Como facilitar o acesso de professores de Língua Portuguesa que atuam na Educação Básica às obras/textos mato-grossenses, uma vez que eles não são apresentados (nem de forma fragmentada) em muitos livros didáticos? Ademais, por que é importante utilizar a literatura produzida em Mato Grosso em nossas escolas? Sabemos que quando um texto tem como assunto/tema algo que faz parte do contexto do seu leitor, motiva ainda mais sua leitura, uma vez que o leitor consegue se identificar com aquela situação apresentada. Em outro artigo já publicado, salientamos:

Por que é importante que o currículo contemple obras regionais? A resposta parece tão óbvia que a pergunta poderia ser igualmente assim considerada. Mas, quando o assunto é ensino, nunca é demais repetir. Se pensamos a literatura como forma de conhecimento e como um "direito de todo cidadão", conforme Candido, não podemos privar esse cidadão da reflexão, do pensamento crítico acerca da realidade do seu entorno, o que é possível por meio de obras cujos temas incidam sobre o local (não apenas como espaço geográfico, mas, sobretudo, local como espaço de reflexão sobre a vivência de seres da natureza, inclusive os humanos, considerados em sua historicidade). (COCCO, 2009, p.56) 
Ao lermos um texto, temos "a captação artística da realidade, não sua mera cópia, é o que determina a perenidade de uma obra de arte, de um romance, de um poema" (CARVALHO, 2004, p. 16). Essa captação artística da realidade é também necessária ao estudante para que ele desenvolva seu senso estético, num processo gradativo que pode principiar pela identificação com os costumes, a paisagem, e com a linguagem, cheia de peculiaridades locais.

Um fator que acaba distanciando a literatura produzida em Mato Grosso do contexto escolar é o acesso dos professores ao acervo bibliográfico, pois não é fácil encontrar exemplares disponíveis nas livrarias da cidade, salvo alguma obra que tenha sido recentemente lançada ou adotada por alguma escola. No ambiente virtual, essa escassez é ainda mais nítida, em sites como Amazon, Saraiva, Livraria Cultura, entre outros, o único escritor mato-grossense que possui obras disponíveis para aquisição é Manoel de Barros. Quanto aos demais, ou não há, ou já estão esgotadas. Nesse aspecto, Mário Cezar Silva Leite (2015, p. 41), corrobora: "não é exagero afirmar que alguns cânones mato-grossenses permanecem, em suas obras, praticamente inéditos para o público menos especializado, embora não sejam cultural e socialmente desconhecidos". Isso constatamos no meio acadêmico, em que várias obras de autores matogrossenses são analisadas em dissertações de mestrado ou teses de doutorado, entretanto, não são lidas e/ou conhecidas pelos professores das escolas públicas nem pelos seus estudantes.

Isso dito, professores mediadores de leitura, podem e, por que não, devem motivar a leitura dos autores regionais, garantindo uma maior proximidade entre o leitor e a obra, uma vez que há assuntos mais específicos de cada região/cidade, fazendo um paralelo entre textos consagrados nacionalmente e os regionais. Conforme Cocco $(2009$, p. 57) enfatiza, quando é notável a ausência de autores regionais no cânone nacional, "o ensino da literatura regional é ainda mais importante, porque contribui para o reconhecimento e a afirmação da diferença. Pensando a literatura e seu ensino em qualquer nível, teríamos a diferença do regional frente ao nacional". Em outras palavras, essa afirmação reveste-se de importância, não para desenvolver uma cultura ufanista, mas para garantir a sobrevivência das peculiaridades diante de possíveis homogeneizações ou apagamento perante a preponderância de outros elementos vindos de outras culturas, para que a diversidade cultural, tão presente em nosso país, seja percebida, valorizada e defendida. 


\section{Letramento literário: um caminho para a formação leitora literária}

Sabemos que a alfabetização tem um momento para terminar, pois quando a criança e/ou o adulto analfabeto desenvolvem a aquisição do sistema convencional da escrita da língua, eles estão devidamente alfabetizados. Em contrapartida, o letramento consiste nas práticas sociais que envolvem a língua, deste modo, perpetua durante toda a vida do indivíduo. Magda Soares que introduziu o termo letramento no Brasil, define-o como sendo:

resultado da ação de ensinar e aprender as práticas sociais de leitura e escrita; o estado ou condição que adquire um grupo social ou um indivíduo como consequência de terse apropriado da escrita e de suas práticas sociais. (SOARES, 1998, p. 39)

Existem várias classificações de letramento, letramentos e multiletramentos. A escola é palco dessa diversidade, onde a aprendizagem pode advir a partir de um texto escrito até outro audiovisual. $\mathrm{O}$ estudante, desde criança, está inserido numa realidade de multiplicidade de comunicação, mídia, enfim, a internet permite interatividade direta no controle da televisão, em que uma criança pode apenas trocar canais na TV aberta, como assistir um vídeo da "Galinha Pintadinha" no Youtube ou Netflix. Entretanto, nossa proposta teve como objetivo o letramento literário que Paulino e Cosson definem como "o processo de apropriação da literatura enquanto construção literária de sentidos” (2009, p. 67, grifo dos autores). Essa construção literária de sentidos é o que podemos dizer nossa aspiração, pois passa por percursos amplos, que incidem desde o papel do professor como agente mediador até a escola, instituição que muitas vezes não consegue garanti-lo desde as séries iniciais até as séries finais.

Rildo Cosson (2012, p. 12) enfatiza a participação da escola no fortalecimento do letramento literário: "daí sua importância na escola, ou melhor, sua importância em qualquer processo de letramento, seja aquele oferecido pela escola, seja aquele que se encontra difuso na sociedade". O texto ou livro literário promove uma reflexão muito além do que está nas linhas, contribui para a formação de um leitor proficiente, quando consegue se apropriar do que leu, bem como se posicionar frente a uma situação cotidiana. Logo, assegurar ao estudante uma construção literária de sentidos, constitui também papel do professor, que é o agente mediador. Assim, "o letramento literário precisa da escola para se concretizar, isto é, ele demanda um processo educativo específico que a mera prática de leitura de textos literários não consegue sozinha efetivar.” (SOUZA, COSSON, 2011, p.102). 
Dito isso, enfatizamos que o ambiente escolar é muito profícuo para desenvolvermos a experiência literária. Destarte, é importante fomentar estratégias diferentes para ampliar a competência leitora, com diversos textos literários, comparando as diferenças entre as gerações, estilos, mostrar a possibilidade de conhecer outros lugares, culturas, ajudando assim o estudante a exercer sua cidadania. Os Parâmetros Curriculares Nacionais elucidam que "o texto literário não está limitado a critérios de observação fatual [...]. Ele os ultrapassa e transgride para constituir outra mediação de sentidos entre o sujeito e o mundo" (BRASIL, 1998, p. 26).

Quando estimulamos a leitura de textos literários, propiciamos uma experiência que poderá ser ou ter sido vivenciada ou não na vida real, de modo semelhante, mas independentemente de ser ou ter sido ou não vivenciada, ela pode provocar uma reflexão, ou algo que inquieta o leitor e, de certa forma, prepara-o para conviver com as diferenças, para exercer o seu papel de cidadão. Paulino (2010) também aborda a importância do texto literário para formação de leitores conscientes de seu papel na sociedade, bem como o papel do professor como mediador escolar da leitura:

Eis, pois, a evidência de que, para romper-se um ciclo de submissão, repetição, padronização, contrário ao letramento literário, é preciso manter viva a discussão sobre valores estéticos e suas funções, estabelecendo, ao mesmo tempo, a consciência do professor, ou do orientador, mediadores escolares da leitura, e, afinal, dois dos principais responsáveis pelas disfunções do livro para crianças. Basta de textos fracos e previsíveis[...]. Vamos ao que interessa: à formação de leitores verdadeiramente conscientes, porque instalados na fortaleza literária, na formação filosófica, para as possibilidades de um mundo que não está pronto ainda, está apenas se formando para as diferenças, para as pluralidades, para a democracia verdadeira. (PAULINO, 2010, p.118)

Salientamos que a mediação do professor é muito importante para o estímulo de práticas literárias no contexto escolar, pois, ao abordar um texto/livro literário o professor pode conquistar um sujeito leitor, ou pode ocorrer o inverso, despertar no estudante uma aversão ao texto/livro literário, devido à mediação equivocada por parte do professor. Entramos numa situação mais complexa, por abranger desde a formação do professor de Letras até um instrumento muito utilizado em sala de aula, o livro didático de língua portuguesa.

Conforme já dissemos, projetos de leitura tendem a ser eficazes no processo de letramento e podem incluir, na bibliografia, textos produzidos no contexto regional em que o aluno esteja inserido, especialmente no caso de regiões em que haja produção qualitativa a qual ainda não esteja presente nos livros didáticos. Essa inserção pode contribuir para o desenvolvimento da autoestima, pode propiciar encontros com escritores, pode contribuir com 
a formação de olhares mais atentos e críticos sobre o lugar onde o estudante se situa. Como já dissemos, esse é um recorte da dissertação de mestrado defendida e orientada respectivamente pelas autoras. Tal dissertação, na sequência, propõe programas de leitura que possam minimizar a tal ausência do texto produzido em contexto do pertencimento do estudante nos livros didáticos.

\section{Considerações finais}

Somos cientes das dificuldades enfrentadas pelos professores no que diz respeito ao trabalho com a leitura do texto literário, ainda mais em se tratando de textos de escritores regionais, com suas obras desconhecidas para grande parte dos professores das escolas públicas do estado. No entanto, a escola não pode deixar de incentivá-la, pois a leitura literária é parte fundamental do processo da formação humana, no sentido de compreensão crítica da realidade e do desenvolvimento da sensibilidade acerca de si e do outro, além do desenvolvimento de importantes habilidades cognitivas como estabelecer relações, fazer inferências, mobilizar informações de outros campos do saber, etc.

Sabemos que letramento literário é um processo que se constrói durante a vida escolar, muitas vezes pode iniciar no meio familiar e continua mesmo após o término dos estudos. Com isso, damos a oportunidade aos estudantes para perceberem que "a boa literatura é sempre uma janela aberta para o mundo. Por meio dela, a vida pode ser observada, usufruída, compreendida, questionada e, em certa medida, vivida" (BRAIT, 2015, p. 133). Como uma boa literatura, também aquilo que é qualitativo na literatura produzida em Mato Grosso pode propiciar aos nossos estudantes o prazer dessa janela que vislumbra o seu mundo e o mundo dos outros.

\section{Referências}

BRAIT, Beth. Literatura e outras linguagens. $1^{\mathrm{a}}$ ed., $2^{\mathrm{a}}$ reimpressão. São Paulo: Contexto, 2015.

BRASIL. Secretaria de Educação Fundamental. Parâmetros curriculares nacionais: terceiro e quarto ciclos do ensino fundamental: língua portuguesa/Secretaria de Educação Fundamental. Brasília: MEC/SEF, 1998.

BRASIL. Ministério da Educação. PNLD 2017: língua portuguesa - Ensino fundamental anos finais / Ministério da Educação - Secretária de Educação Básica SEB - Fundo Nacional de 
Desenvolvimento da Educação. Brasília, DF: Ministério da Educação, Secretária de Educação Básica, 2016.

BUNZEN, Clecio; MENDONÇA, Márcia. Múltiplas linguagens para o ensino médio. São Paulo: Parábola Editorial, 2013.

CARVAlHO, Carlos Gomes de. Panorama da Literatura e da cultura em Mato Grosso. Cuiabá: Verdepantanal, 2004.

CAVALCANTE, Mônica Magalhães. Os sentidos do texto. 1. Ed. São Paulo: Contexto, 2016.

COCCO, Marta Helena. O lugar da literatura regional no ensino. Revista Ecos, Ed. 008, Dez 2009, p. 55-60. Disponível em:

http://periodicos.unemat.br/index.php/ecos/article/view/953/959 . Acesso: agosto de 2016.

COSSON, Rildo. Letramento literário: teoria e prática. 2 ed. São Paulo: Contexto, 2012. , Rildo. Círculos de leitura e letramento literário. São Paulo: Contexto, 2014.

MAGAlHÃES, Hilda Gomes Dutra. História da Literatura de Mato Grosso: Século XX. Cuiabá: Unicen Publicações, 2001.

MATO GROSSO, Secretaria de Estado de Educação. Orientações Curriculares: Área de Linguagens: Educação Básica. Cuiabá: Gráfica Print, 2012.

PAULINO, Graça. Das leituras ao letramento literário 1979-1999. Belo Horizonte: Fae/UfMG; Pelotas: UFPel, 2010.

, Graça; COSSON, Rildo. Letramento literário: para viver a literatura dentro e fora da escola. In: ZILBERMAN, R.; RÖSING, T.M.K. (orgs). Escola e leitura: velha crise, novas alternativas. São Paulo: Global, 2009. p. 61-79.

PINHEIRO, Hélder. Poesia em sala de aula. 3 ed. Campina Grande: Bagagem, 2007.

RANGEL, Egon de Oliveira. Letramento literário e livro didático de língua portuguesa: "Os Amores Difíceis". In: PAIVA, Aparecida; MARTINS, Aracy; PAULINO, Graça; VERSIANI, Zélia (orgs.). Literatura e letramento: espaços, suportes e interfaces - O jogo do livro. Belo Horizonte: Autêntica, 2003. p. 127-145.

ROUXEL, Annie. Práticas de leitura: quais rumos para favorecer a expressão do sujeito leitor? Trad. Neide Luzia de Rezende e Gabriela Rodella de Oliveira. Cadernos de pesquisa, v.42, n.145, p.272-283, jan./abr, 2012. Disponível em: $<$ http://www.scielo.br/pdf/cp/v42n145/15.pdf $>$. Acesso em: 16 outubro 2017.

SILVA, Danielle Amanda Raimundo; FRITZEN, Celdon. Ensino de literatura e livro didático: uma abordagem a partir das pesquisas na pós-graduação brasileira. Revista Contrapontos, V. 12, N. 3, 2012. p. 270-278. Disponível em: $<$ http://siaiap32.univali.br/seer/index.php/rc/article/view/2236/2377>. Acesso: 10 agosto 2016. 
SOUZA, Renata Junqueira; COSSON, Rildo. Letramento literário: uma proposta para sala de aula. In: Acervo digital da Unesp. 2011. Disponível em: $<$ https://acervodigital.unesp.br/bitstream/123456789/40143/1/01d16t08.pdf. $>$. Acesso em: 14 abril 2016.

ZILBERMAN, Regina. A escola e a leitura da literatura. In: Regina; RÖSING, Tania M.K. (orgs). Escola e leitura: velha crise, novas alternativas. São Paulo: Global, 2009. p. 17-39. 